\title{
APPRAISAL OF PERFORMANCE MANAGEMENT PRACTICES AND EXCELLENT PERFORMANCE INDICATORS IN PUBLIC HIGHER EDUCATIONAL INSTITUTIONS
}

\author{
Yamima Dauda \\ Department of Management and HRM \\ Ghana Communication Technology University \\ Takoradi, Ghana
}

\begin{abstract}
The excessive attention on performance evaluation in tertiary education in current times should be viewed in consonance with globalization. Globalization has had a complete makeover effect on advanced academic establishments as a consequence of its widening, deepening and speeding up of worldwide connectedness. Performance is in essence the amount of effort a worker puts in to help an establishment achieve its targets. A comparative analysis of the resemblances and variations in PM practices were highlighted to ascertain best practices in academic institutions. The study aims at ascertaining performance management (PM) practices as well as excellent performance indicators in public higher educational institutions (HEIs) of Ghana.

The study takes the form of a case study where the University of Cape Coast (UCC) in the Central region and the Takoradi Technical University (TTU) in the Western region were selected as units of analysis. Using the simple random technique, 141 respondents were selected from the total population of 173 using the Yamane (1967) formula. Data was analyzed using a quantitative approach. Setting performance objectives, setting performance standards and setting performance targets were the variables studied for performance Management practices. Conformity to standards and service quality were the variables studied for excellent performance indicators. The findings of the study reveal that most of the respondents confirm to the observant of performance practices as well as excellent performance indicators in their institutions.
\end{abstract}

\author{
Bayuasi Nammei Luki \\ Department of Management and HRM \\ Ghana Communication Technology University \\ Takoradi, Ghana
}

\begin{abstract}
Keywords: Performance Management, performance indicator, Higher Educational Institutions
\end{abstract}

\section{INTRODUCTION}

In recent years, there has been a paradigm shift in the direction of designing and implementing programs intended to achieve developmental goals. Undoubtedly, the desire for sustainable development in various political, economic and social spaces, require forces that have the ability to perform their duties, as well as having sufficient motivation to do so [4]. Performance is in essence the amount of effort a worker puts in to help an establishment achieve its targets. Performance management (PM) is regarded as a division of the operations of Human Resource Management (HRM) that connects personal effort to establishment targets [6].

According to [2] personal and group PM point to activities where individual performances are handled to hasten organizational performances. Supervisors toil with their workers to decide prospects, monitor products and reward performance or competences so as to develop worker output, with the eventual aim of positively influencing organizational performance [7]. Performance management is defined differently by various authors. [6 \&10] posit that progressively, PM schemes are being acknowledged as methods of supervising personal output in ways that compliment staff appraisal. These schemes offer opportunities to closely connect into the objectives of the organization; hence the resulting outcome is more likely to meet organizational needs. To [3], PM is seen as a strategic and integrated approach in bringing continued success 


\section{International Journal of Engineering Applied Sciences and Technology, 2021 \\ Vol. 5, Issue 12, ISSN No. 2455-2143, Pages 27-32 \\ Published Online April 2021 in IJEAST (http://www.ijeast.com)}

to organizations by enhancing the performance of staff and by developing the competences of contributors. The main focus of performance management is achieving organizational objectives, attaining better result from individual participants, and developing employees in terms of behaviour and output. It also focuses on sustained reviews to drive the employees towards doing the right things at the right times through teamwork [6]. This managing procedure is also found in education. Considering the rapidly increasing number of educational institutes, and the pursuit of top standards in academia, it has become important to push workers and the institutes in the direction of excellence. Tertiary education is essential in producing human resources for nations and should be accorded national importance.

PM of staff of tertiary academic institutes is essential because of the improving academic values and accomplishments. For any entrepreneurial venture as well as in academia, the most important factors are the value of the facility and the contentment of patrons. Thus, staff PM is a never-ending course of progress, to establish and observe development in relation to institutional goals, identify outlook for growth and contrast output with internal and external standards. In education, the strengths and weaknesses of the institutes are revealed through PM. Objectives are achieved by the utilization of the range of PM frameworks to assess a person, the unit, the schemes and (or) the whole institute [10]. PM is a slow process of improving a person's output and establishment efficiency in the realization of its goals and responsibilities. Managing staff performance comprises: estimating labor output goals, always keeping an eye on work output, improving the efficiency of staff and from time to time, assessing productivity. PM is a system grounded on set objectives directed at making certain that establishment processes are at hand to improve output of the workers and the establishment in general. PM is a procedure encompassing a whole establishment and centres on appraising and aiding the merit of the staff. It additionally comprises motivational objectives and the related motivational ideals so that a bond is plainly created. There is a conjecture that there exists a progressive relationship between efficient performance assessment and academic excellence in advanced educational institutes.

\section{PROBLEM STATEMENT}

The desire for sustainable development persuades organizations to focus more than ever on their manpower development and this primary responsibility rests on the human resources management (HRM) department. Hence, the human resource (HR) personnel must perform their duties adequately by providing suitable substrates for talented and capable forces in the organization to fulfill their duties efficiently [1]. However, the effectiveness of skilled personnel will be limited unless they are motivated to perform their jobs [12]. Thus, [2 \& 6] postulate that, despite the central roles played by higher educational Institutions (HEIs) in the development of high quality, multi-skilled units of human capacities and knowledge base required for national development, the challenges of human resource management in HEIs still remains a problem of how to adequately manage workers operating within the higher education sector to enhance excellent performance.

Hence, HEIs can only boost of superior outcomes, if they can improve their professional skills through the use of performance management systems. Thus, right recruitment, right training and right induction followed by faultless monitoring and measuring are but decisive factors in business and industry. Altogether, there is a constant attention on the human factor in the scheme of things; this may not be the case in education. On the educational front so far, there appears to be no such measure of care, close monitoring and performance analysis of human resource management. In order to promise quality human capital output through education, it is a basic requirement that HEIs must follow the methodology of industry and commerce because education can be treated as an industry in the service sector.

Hence, effectively undertaken human resource management practices in HEIs can serve as a tool for ensuring that excellent outcome is attained in higher educational institutions [13]. Therefore, this paper seeks to assess performance management practices and quality performance indicators in public HEIs of Ghana.

\section{METHODOLOGY}

\subsection{Research Design}

Research design is the universal plan of how the research questions would be answered. It is the theoretical arrangement within which research is conducted. It is made up of a blue print for the compilation, measurement and analysis of data [15]. The study took the form of a survey, and therefore made use of a descriptive survey design. It relied on the quantitative method, where closed ended question were used to solicit information from the respondents.

\subsection{The Study Population}




\section{International Journal of Engineering Applied Sciences and Technology, 2021 \\ Vol. 5, Issue 12, ISSN No. 2455-2143, Pages 27-32 \\ Published Online April 2021 in IJEAST (http://www.ijeast.com)}

[15] describe a study population as the whole group that the research focuses on. The target population of the study was employees from the HR department of the University of Cape Coast and Takoradi Technical University. The HR department of the University of Cape Coast has a population of 64 , while that of Takoradi Technical University has a population of 109. Therefore, the total number of employees for the study was one hundred and seventy-three (173), consisting of thirty-four (34) senior staff and one hundred and thirty-nine (139) junior staff.

\subsection{The Sampling Size and Sampling Techniques}

Sampling is the selection of a subset of individuals from within a population to estimate characteristics of the whole population. The sample must have sufficient size to warrant statistical analysis. The main function of the sample is to allow the researchers to conduct the study to individuals or objects from the population so that the results of their study can be used to derive conclusions that will apply to the entire population [8]. Out of the total population of one hundred and seventy-three (173), the total sample was 141 , however only 100 participants returned the questionnaire. This was selected based on Yamane's (1967) formula, which is used to calculate each institution's population separately, before putting it together to arrive at the total sample size. Simple random sampling was employed to select the respondents in this study. In statistics, a simple random sample is a subset of individuals (a sample) chosen from a larger set (a population). Each individual is chosen randomly and entirely by chance, such that each individual has the same probability of being chosen at any stage during the sampling process, and each subset of the population has the same probability of being chosen for the sample as any other subset of the population. Thus, the sample to be selected would be chosen at random from any of the two HR departments.

\subsection{Data collection Instrument}

The researcher used questionnaire as the tools for obtaining the necessary information for the research. A questionnaire is a Pro-forma containing an array of questions to elicit information from the respondents. [14], defined questionnaire as a set of questions presented to respondents. It is used to collect data and is very flexible because it can be administered in person, by phone or online. The questionnaires for the study were made up of close ended questions, also called structured questions.

\subsection{Data Analysis Method}

After the administering and retrieval of questionnaires from the field, the responses were edited to correct errors in the data collected and also to check for accuracy. The data gathered from the field were coded and generated into readable, descriptive and tabular form, and analyzed and interpreted using the Statistical Package for Social Science (SPSS) software. Finally, information from data analysis was summarized and conclusions, inferences and recommendations were made to the HR departments of the study institutions.

\section{RESULTS AND DISCUSSION}

This section presents the primary findings of the empirical investigation carried out within the two case study institutions (two public HEIs) in Ghana. This section aims to present and analyse the data obtained from self-administered questionnaires.

\subsection{Reliability of instrument}

Cronbach's alpha measurement of internal consistency was used to appraise the general dependability of the measurement scale, where alpha approximates the fraction of the total variance that is not due to error which signifies the reliability of the scale. The suggested least acceptable level of reliability "alpha" was 0.60 using [9] principle. Table 1 delivers a summary of the reliability analysis.

Table 1 Results of the Reliability Tests

Cronbach's Alpha N of Items

Source: field study (2018)

As shown in Table 1 the alpha values for academic quality scales is 0.80 all of which are above 0.70 . So, the scales that are adopted in this study are considered reliable per the sample collected.

Table 2 comparison of performance appraisal variables in UCC and TTU

\begin{tabular}{|c|c|c|}
\hline $\begin{array}{l}\text { PERFOMANCE } \\
\text { MANAGEMENT VARIABLES }\end{array}$ & UCC & TTU \\
\hline Setting performance objectives & $\begin{array}{c}\text { MEAN } \\
1.09\end{array}$ & $\begin{array}{c}\text { MEAN } \\
1.48\end{array}$ \\
\hline Setting performance standards & 1.42 & 1.41 \\
\hline Setting performance targets & 1.41 & 1.30 \\
\hline
\end{tabular}

(Source: field survey 2018) 


\section{International Journal of Engineering Applied Sciences and Technology, 2021 \\ Vol. 5, Issue 12, ISSN No. 2455-2143, Pages 27-32 \\ Published Online April 2021 in IJEAST (http://www.ijeast.com)}

The comparison of performance management (PM) variables from the two public academic institutions revealed that the respondents from both institutions strongly agreed that setting performance objectives was a key PM practice in their institutions, with mean scores of (1.09 for UCC and 1.48 for TTU).

This implied that UCC had slightly better performance-based objectives than TTU. This was to be expected because UCC being a far older institution must have built up a good performance record over the years, therefore giving it that slight advantage over TTU.

On comparison of mean scores ascribed to setting of performance standards, it was shown that the two institutions did not have differing opinions on that variable. Respondents from the two institutions strongly agreed that setting performance standards was a pm practice in their institutions with mean values of (TTU 1.41 and UCC 1.42). This implies that performance standards at TTU were marginally better than those at UCC. This is likely to be a result of TTU trying to carve a niche for itself as a growing university.

On comparing setting performance targets, respondents from the two institutions strongly agreed that setting performance targets was a significant variable in pm practice of their institutions. However, respondents of TTU were rather more confident with a mean score of (1.30), while UCC had a mean score of (1.41). It is probable that TTU as a fresh university adheres more to best practices.

Table 3 Descriptive Statistics of PM Practice in Public Academic Institutions

\begin{tabular}{ccc}
\hline Statistic & Mean & $\begin{array}{c}\text { Std. } \\
\text { Deviation }\end{array}$ \\
\hline Setting performance objectives & 1.41 & 0.847 \\
Setting performance standards & 1.30 & 0.710 \\
Setting performance targets & 1.35 & 0.729
\end{tabular}

(Source: field survey 2018)

On examination of the mean scores and standard deviations of setting performance objectives as a variable of pm practice in public HE institutions, the findings showed an aggregate mean of (1.41). This suggested the likelihood of strong agreement with all statements. The standard deviations of (0.847) specify that the spread was somehow broad, implying that the respondents were comparatively inconsistent in the manner they answered the questions.
Examination of the mean scores and standard deviations of setting performance standards as a variable of $\mathrm{PM}$ practice in public $\mathrm{HE}$ institutions revealed a cumulative mean of (1.30). This indicates an inclination towards strong agreement with all statements. The standard deviations of (0.710) specify that the spread was somehow broad, denoting that the respondents were somewhat incoherent in their responses.

Analyzing the mean scores and standard deviations of setting performance targets as a variable of $\mathrm{pm}$ practice in public HE institutions, the results showed an aggregate mean of (1.35). This pointed towards strong agreement with all the statements. The standard deviation of (0.729) showed that the spread was relatively broad, inferring that the respondents were somewhat contradictory in their answers. The outcome implied that the respondents viewed setting performance standards as the most significant pm variable with a mean score of (1.30). The next greatest significant variable was setting performance targets with a mean score of (1.35), while the least of the three was setting performance objectives with a mean score of (1.41), using a 5-point scale.

Table 4 Comparison of Quality Performance Indicators in UCC and TTU

\begin{tabular}{ccc}
\hline ACQ & UCC & TTU \\
\hline Service quality & MEAN & MEAN \\
1.59 & 1.85 \\
Conformity to standards & 1.47 & 1.39 \\
\hline (Source: field survey 2018) & &
\end{tabular}

The comparison of excellence performance indicators from the two public academic institutions reveals that the respondents from both institutions moderately agreed that service quality is an indicator of excellence performance, with mean scores of (1.59 for UCC and 1.85 for TTU). However, the results showed that respondents at UCC were more positive than those at TTU. This implied that service quality at UCC was slightly better than that at TTU. This might be due to the long experience of UCC as a top-notch university, while TTU was only recently upgraded from a polytechnic into a university.

Comparing the mean scores of conformity to standards as an excellence performance indicator from UCC and TTU, the respondents strongly agreed that conformity to standards was a key quality performance indicator with a mean response of (1.47 for UCC, and 1.39 for TTU). This implied that respondents at TTU were slightly more optimistic than respondents at UCC on 


\section{International Journal of Engineering Applied Sciences and Technology, 2021 Vol. 5, Issue 12, ISSN No. 2455-2143, Pages 27-32 \\ Published Online April 2021 in IJEAST (http://www.ijeast.com)}

conformity to standards as a measure of excellence performance. It was likely as a result of TTU enforcing best practices and encouraging service excellence.

Table 5 Descriptive Statistics of Excellence Performance Indicators in Public Institutions

\begin{tabular}{ccc}
\hline Quality Performance Indicator & Mean & $\begin{array}{c}\text { Std. } \\
\text { Deviation }\end{array}$ \\
\hline Service quality & 1.73 & 0.513 \\
Conformity to standards & 1.43 & 0.640 \\
\hline
\end{tabular}

(Source: field survey 2018)

The analysis disclosed that service quality in public HEIs had a mean score of (1.73). This suggested a movement towards moderate agreement with all statements. The standard deviation of (0.513) specified that the spread was relatively broad, implying that the respondents were somewhat inconsistent with their answers. Conformity to standards in public HEIs had a mean score of (1.43). This suggested a leaning towards strong agreement with all declarations. The standard deviation of (0.640) implied that the spread was comparatively wide, suggesting that the interviewees were comparatively inconsistent in the manner they answered the questions. The result implied that the respondents viewed Conformity to standards as the most significant excellence performance indicator with a mean score of (1.43), while the least of the two was service quality with a mean score of (1.73), using a 5point scale

\section{CONCLUSIONS}

In summary the study reveals that most of the respondents confirm that, pm practices as well as excellent performance indicators were practice in their institutions. Performance management variables as well as excellent performance indicators were investigated accordingly. Subsequently, the following conclusions were drawn. The study reveals that human resource management best practices need to be tailored to focus on enhancing excellence in performance. Performance management best practices need to be clearly stated to enable the measurement of superior performance in the institutions.

\section{The Recommendation}

The findings of the study have practical implications to the study institutions where the research work was conducted. Thus, the following recommendation highlights key areas that would be helpful to management of the study institutions in enhancing excellent directions. Performance management variables must be clearly set and aligned with superior performance indicators for effective staff management in enhancing superior performance.

\section{REFERENCENCES}

[1] Andersson, C., (2007) Teacher Density and Student Achievement in Swedish Compulsory Schools, Working Paper 2007: 4, Institute for Labour Market Policy Evaluation, (IFAU), Uppsala.

[2] Armstrong, M. and Baron, A. (1998) Performance Management: the New Realities. Wiltshire, Cromwell Press, CIPD.

[3] Bates, R.A. \& Holton, E.F. (1995) Computerized Performance Monitoring- a review of human resource issues. Human Resource Management Review. Vol 5, issue 4. Winter 1995. pp 267-288.

[4] Barnett, W. S., (1995) Long-term Effects of Early Childhood Programs on Cognitive and School Outcomes. The Future of Children 5, 25-50.

[5] Cronbach, L. J. (1951) Coefficient alpha and the internal structure of tests, Psychometrika, 16, 297334.

[6] Dauda, Y. \& Luki, B. N. (2020). A Comparative Review of Performance Appraisal and Performance Management. International Journal of Education and applied research (JEAR Vol. 10, Issue 2, July - Dec 2020)

[7] Den Hartog, D.N., Boselie, P. and Paauwe, J., (2004) Performance Management: A Model and Research Agenda, Applied Psychology: An International Review, Vol. 53, No 4, Pp. 556-569.

[8] Castilo, J. J., (2009) Research Population, (online). available from: Explorable. Com: https//explorable.com/research-population

[9] Hair, J. F. Jr., Anderson, R. E., Tatham, R. L. and Black, W. C., (1998) Multivariate Data Analysis, (5th ed.), Prentice-Hall International, Upper Saddle River, NJ.

[10] Khalid, S., Knouzi, N., Tanane, O. \& Talbi, M. (2014). Balanced scoreboard, the performance tool in higher education: Establishment of performance indicators. $5^{\text {th }}$ World Conference on Educational Sciences - WCES 2013. Procedia - Social and Behavioral Sciences 116 (2014) 4552 - 4558

[11] Sulemana I., (2013) the contribution of Ghana's development of polytechnics of national prosperity and challenges to the stainability- focusing on staff turnover. PhD Thesis, University of Edinburgh [12] Oladipo Jimoh A., (2011) Strategic Human Resource Management and organizational performance in Nigeria manufacturing sector: An empirical investigation internal journal of Business and Management, Vol6.N.9 
[13] Omebe, C. A., (2014) Continuous Assessment in Nigeria: Issues and Challenges; BEST: International Journal of Humanities, Arts, Medicine and Sciences (BEST: IJHAMS), pp89-96

[14] Saunders, M. Lewis, P. \& Thornhill, A. (2003) Research Methods for Business Students (3rd Ed). Harlow, Pearson Education Ltd.

[15] Saunders, M., Lewis, P., and Thornhill, A., (2007) Research Methods for Business Students, Pearson Professional Limited, London.

[16] Yamane, T., (1967) Statistics, An Introductory Analysis, 2nd ed., New York: Harper and Row. 